\title{
Improving Approaches to the Formation of Enterprise's Marketing Budgets
}

\author{
OLENA BONDARENKO ${ }^{1}$, SVITLANA KOVALCHUK ${ }^{2}$, SERGII RODIONOV ${ }^{3}$, MARIA MIROSHNIK ${ }^{4}$, \\ OLENA KITCHENKO ${ }^{5}$, LESYA FRANCHUK ${ }^{6}$ \\ ${ }^{1}$ Department of Marketing, KYIV NATIONAL UNIVERSITY OF TRADE AND ECONOMICS, UKRAINE. \\ 2,6Department of Marketing and Trade Entrepreneurship, KHMELNYTSKY NATIONAL UNIVERSITY, UKRAINE. \\ ${ }^{3}$ Department of Economics and Marketing, SIMON KUZNETS KHARKIV NATIONAL UNIVERSITY OF ECONOMICS, \\ UKRAINE. E-mail: I.a.I.a@ukr.net \\ 4,5 Department of Economics and Marketing, NATIONAL TECHNICAL UNIVERSITY «KHARKIV POLYTECHNIC \\ INSTITUTE», UKRAINE.
}

\begin{abstract}
This article discusses the importance of optimizing advertising budgets for enterprises in the face of fierce competition for the consumer. It highlights the principles that business owners should consider when developing a marketing budget and notes the change in the influence of marketing in the sales funnel. The process of optimization of advertising budgets is presented.

Also, the main approaches and methods of forming the marketing budgets of enterprises are highlighted. The method is considered in detail, taking into account the effectiveness of the use of marketing budgets. And recommendations are given on the allocation of budgets within advertising channels, depending on the goals and size of the enterprise.
\end{abstract}

Keywords: advertising channel, CEO, enterprise, marketing budget

JEL Classification: M30, M31, M37 


\section{Annotation.}

Marketing is the only condition for the survival of a subject of the economy in conditions of fierce competition and rising costs. The competition for consumers' attention and their purchasing budgets has never been greater [1-2].

A marketing program, of course, cannot be implemented without an adequate budget [3-4]. In the context of the global pandemic and crisis, digital provides most of the advertising budgets, and in 2021 it will account for more than half of all expenses worldwide.

The size of marketing costs depends on the size of the enterprise, its role in the market, the type and originality of products, the degree of market development, the nature of the marketing strategy.

Calculating the number of deductions for marketing is a rather difficult task due to the presence in it of a significant number of variables that cannot be accurately recorded, which each company must solve independently, based on the goals set [5-6]. That is why the issue of improving approaches to the formation of marketing budgets of an enterprise is so urgent in modern conditions.

During a time of declining sales and profits, it is often possible to face a situation where the sales department responds to the demand for an increase in sales: "more advertising - more sales", "less advertising - fewer sales". The result of such requirements is an increase in advertising budgets, up to the receipt of an operating loss of activity.

This, in turn, can create serious financial problems for the organization if the market does not adequately respond to increased advertising activity. In this case, the problem lies in the inconsistency of the product or service with the existing market requirements.

\section{Theoretical ground}

The modern world forces companies to develop new systems of indicators that allow an enterprise to monitor the profitability of marketing costs.

CEOs want to know how sales and profits have changed, rather than how much knowledge, awareness, and preference has emerged from marketing programs.

For example, marketers at the Coca-Cola Company must calculate the financial implications of their marketing programs both at the stage of budgeting and at the end of the programs.

Marketers must be able to reason like financiers. One of the first steps in this direction is to analyze the profitability of an individual product, market segment, distribution channel and consumer [7-8].

The increase in marketing costs and the decrease in many cases of the effectiveness of marketing programs have led to a more targeted targeting of clearly defined groups of consumers. This leads to the abandonment of "free-spending" marketing, cutbacks in marketing budgets, and a shift to marketing based on ROI.

For any business, marketing is essential for the growth of the enterprise's profits. However, many companies do not allocate enough money for marketing or spend the money allocated for marketing ineffectively.

Here are five principles small business owners need to keep in mind when developing a marketing budget (Fig. 1).

Before creating a marketing budget, a small business owner needs to know which channels to use to generate leads. This requires a deep dive into the target audience to find out as much information as possible. 
Figure 1. Principles of an effective marketing budget.

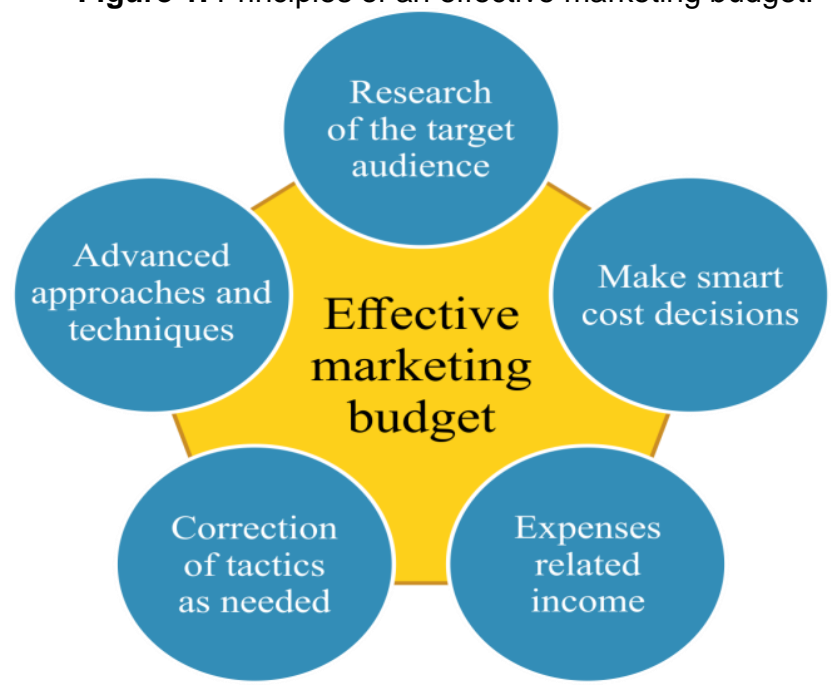

Some questions the enterprise should ask itself:

- what is your target age group?

- what is the income level of your target audience?

- what is your target geographic area? Suburb? Big city? Countryside?

- which brands regularly interact with your target audience?

All this information can be obtained by researching the enterprise's industry on the Internet. Once it understands leads, it can figure out how to best manage them through the sales funnel (Fig. 2).

Figure 2. Changing the role of marketing in the sales funnel.

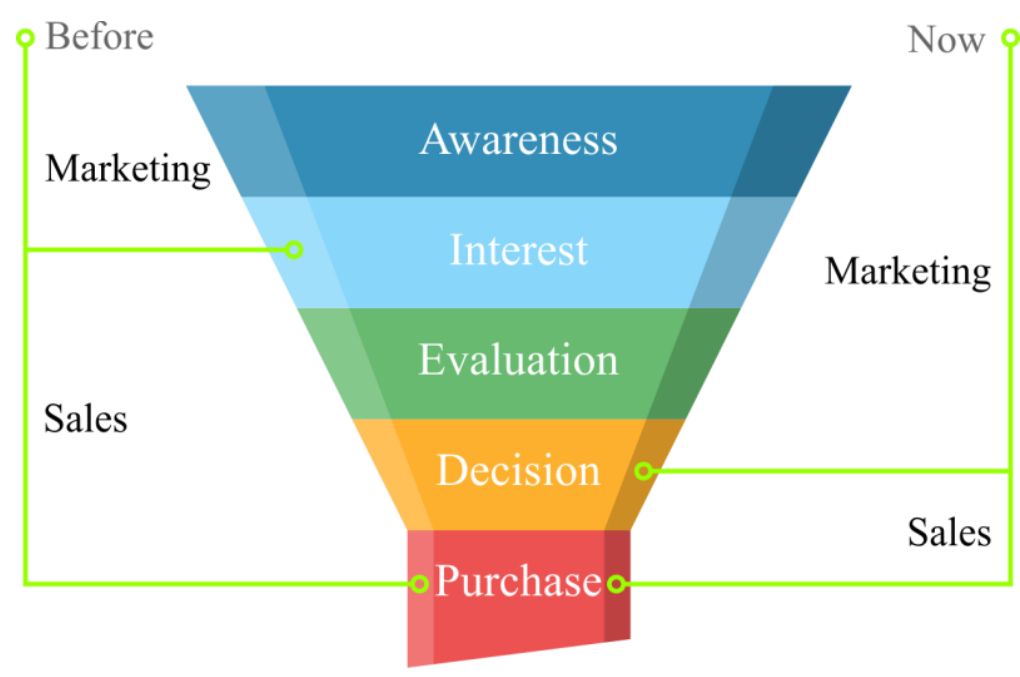

Creating an effective marketing budget requires a deep dive into the sales funnel, in which the enterprise need to track results throughout the entire cycle [9].

Marketing strategies are now so ambitious that it is not only unprofitable to perform any operations manually, but it is often physically impossible. Automation algorithms process a huge amount of data in a second and greatly facilitate the work [10].

If some creative tasks are performed only by a person (for example, creating letters, logos, writing creative texts, etc.), then routine actions, for example, analyzing user behaviour on pages and in letters, sales funnels and other interaction with customers, are successfully entrusted to machines.

To get a good idea of marketing needs, the enterprise need to examine the following funnel data:

- the number of visits to the store or site per month; 
- the number of requests converted to a list of leads;

- cost of creating requests;

- the number of hits that were subsequently converted to purchases;

- the number of opportunities close to new deals;

- average profit for a new trade.

Modern marketing automation software and systems are capable of analyzing both online and offline data.

Marketing automation services include ESP and CDP services.

ESP services are services for sending email newsletters. In addition to the main task (email newsletters), they also solve others: creating landing pages and conversion funnels, A / B testing, segmentation of the contact base, setting up letter chains. Many of these systems can integrate with CRM systems.

CDP services are systems that analyze and aggregate data about customers and their behaviour collected through various communication channels (website, email, SMS, web push notifications, etc.) to achieve set goals, for example, traffic growth, conversion, increase in sales, etc.

As those and other services become more advanced, they resemble each other but still do not completely replace each other.

Marketing automation programs help the enterprise build relationships with customers through automated messages and provide a higher quality of service and analyze and increase conversions, thereby more completely spending its marketing budget.

\subsection{Marketing budget}

In a broad sense, the marketing budget should be understood as a clearly formulated list of the company's income and expenses for a certain period [11-12].

A marketing budget has several features:

- it is not always developed for a certain period; it can be developed for a specific marketing event;

- expenses of the company are the expenses of the company for marketing activities - advertising and PR-actions and campaigns, sales and demand stimulation, entertainment expenses, etc.;

- in the role of income are quantitative and qualitative operations of the effectiveness of marketing activities.

In general, planning a marketing budget for a company can be represented as a balanced linking of resources and needs for them, indicating the sources of resources and their distribution. The marketing budget development process is shown in Figure 3.

The first part includes expenditure items of the budget, i.e. it is characterized by the targeted orientation of the allocation of resources and the quantitative and qualitative characteristics of the budget. As a rule, this part is compiled using a cost estimate - a documented amount of costs (labour, money, material) necessary for implementing the complex and individual marketing activities.

The second part is the revenue items of the budget, i.e. the ratio of the sum of the effectiveness of the complex and individual marketing activities to the sum of resources spent on its planning, development and implementation. Here, the level of return on costs and the degree of use of funds for marketing are determined, i.e. profitability and profitability of marketing activities, their economic feasibility. 
Figure 3. The process of optimizing the enterprise's marketing budget Optimization of the marketing budget.

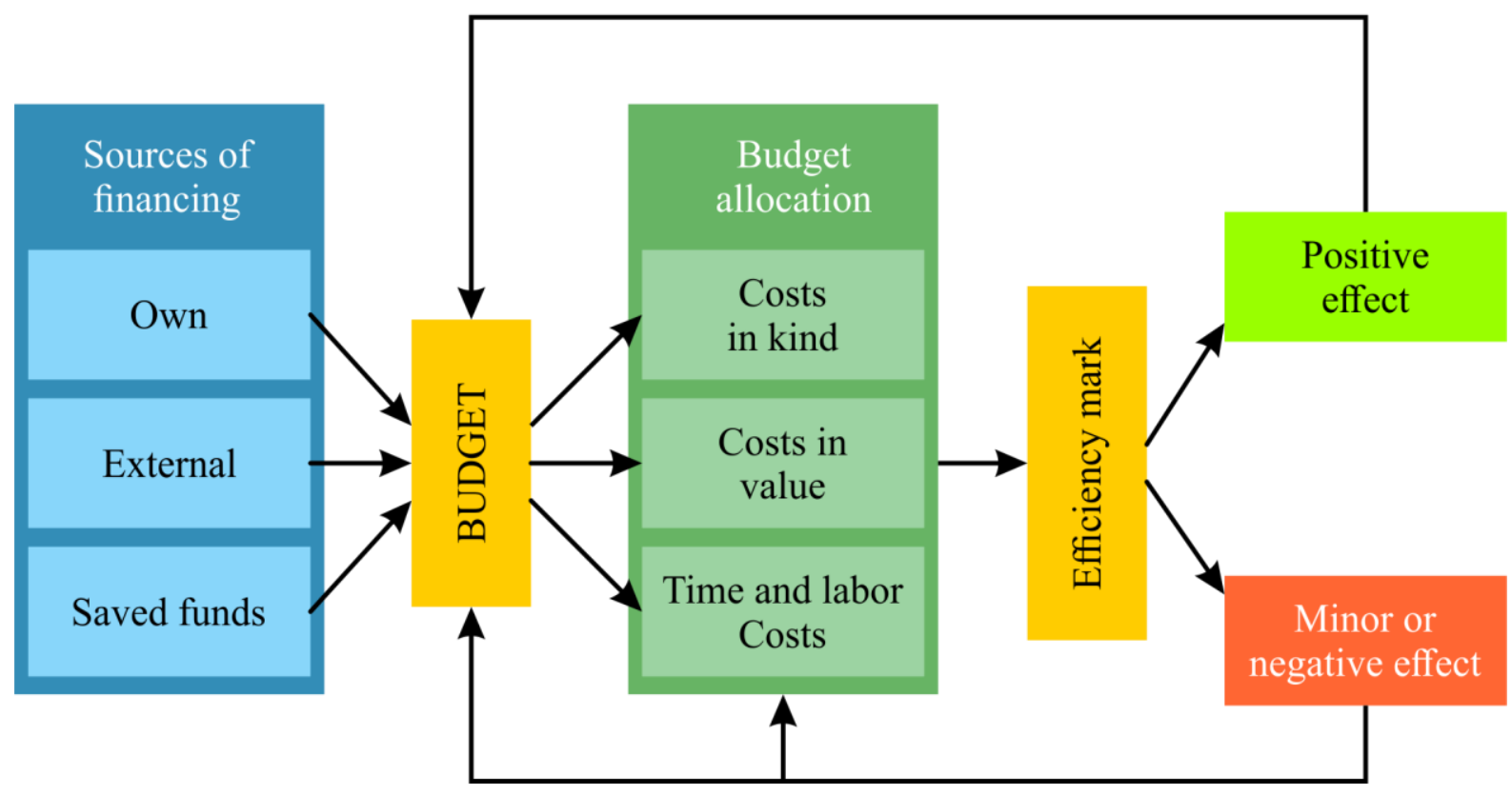

\subsection{Review of approaches to forming a marketing budget}

Almost no modern approach to the formation of marketing budgets of an enterprise answers the question - through which marketing channels and in what quantity within these channels to distribute the advertising budget. That is, they answer the question "how much" to spend rather than how to distribute this "how much".

There are several main approaches to calculating the advertising budget. In them, the volume of the advertising budget is calculated:

- depending on the size of the company's turnover.

- depending on the volume of advertising budgets of competing firms.

- based on the funds remaining after distribution for all other needs.

- based on the criterion of optimality of advertising costs.

Approach 1. Calculation of the advertising budget depending on the turnover.

This approach includes five methods: determining the volume of the advertising budget as a percentage of sales, the method for determining the importance of the advertising budget, taking into account the goals and objectives, the Yule model, the Vidal-Wolf model and the ADBUDG model.

The methods of this approach assume that the increase in the company's turnover is proportional to the advertising inflows.

1. The method of determining the volume of the advertising budget as a percentage of sales.

In this method, the advertising budget is estimated concerning the actual turnover at the moment:

$$
E_{A}=k * S_{0}
$$

where $E_{A}$ - advertising budget (advertising costs);

$k$ - prevailing in the market (or in the firm itself) indicator of deductions for advertising concerning sales;

$S_{0}-$ the company's turnover at the time of the advertising budget estimation 
2. The method of determining the volume of the advertising budget, taking into account the goals and objectives

This method takes into account the volume of desired sales:

$$
E_{A}=p * n_{0} * \frac{S}{S_{\max }}
$$

where $p$ - the cost of one so-called rating unit;

$n_{0}$ - the number of rating units required for conditionally $100 \%$ coverage of the target audience;

$S$ - the desired level of sales;

$S_{\max }$ - the maximum level of sales (conditionally $100 \%$ coverage of the target audience).

3. Yule's model.

Here is a general formula for this model:

$$
E_{A}=p * n_{0} * \frac{1}{k_{0} * k} \frac{N}{N_{\max }}
$$

where $p$ and $n O$ have, in fact, the same values as for the previous method;

$N_{\max }$ - the number of potential clients of the advertiser;

$N$ - the number of clients who will become regular clients of this company;

$k$ - the ratio of the number of clients of a given firm who have become permanent to the number of clients who will try the goods of this firm;

$k_{0}$ - the ratio of the number of customers who try the product of this company to the number of those who saw the advertisement of this company.

4. Vidal-Wolf model.

Here is the formula that is used in this model as a base one:

$$
S^{\prime}=k_{1} * \frac{S_{\max }-S_{0}}{S_{\max }} * E_{A}-k_{2} * S_{0}
$$

where $S^{\prime}$ - change in the level of sales compared to the current one;

$k_{1}$ - constant of the turnover reaction to advertising;

$S_{\max }$ - the level of market saturation with this product (work, service);

$S_{0}$ - current sales volume;

$k_{2}$ - constant sales decrease in the absence of advertising costs.

5. The ADBUDG model.

This method uses the following formula as a base:

$$
P=P_{\min }+\left(P_{\max }-P_{\min }\right) * \frac{E_{A}^{\gamma}}{\delta+E_{A}^{\gamma}}
$$

where $P$ - the market share that the firm wants to occupy;

$P_{\min }$ - the market share that the firm will take with zero advertising $(\mathrm{EA}=0)$;

$P_{\max }-$ the market share that the company will occupy with the highest level of advertising $\left(\mathrm{E}_{\mathrm{A}}=\right.$ $\max )$;

$\gamma$ - the coefficient of sensitivity of the reaction function;

$\delta$ - attenuation coefficient.

From here it is easy to find the amount of the advertising budget: 


$$
E_{A}=\left[\frac{\delta *\left(P-P_{\min }\right)}{P_{\max }-P}\right]^{1 / y}
$$

Approach 2. Calculation of the advertising budget depending on the volume of advertising budgets of competing firms

In general terms, the formula looks like this:

$$
E_{A}=k * \sum_{i=1}^{N} E_{A_{i}}
$$

where $E_{A i}$ - the advertising budget of the i-th competitor company;

$N$ - the number of competing firms;

$k$ - coefficient of proportionality between the sum of advertising budgets of competing firms and the advertising budget of the given firm.

This approach to the formation of a marketing budget includes the following methods:

1. The method of evaluating the advertising budget, taking into account the practice of competing firms.

In this method, the volume of the advertising budget is calculated as the average between the volumes of the advertising budgets of competing firms:

2. The method of equity participation in the market.

In its pure form, this method uses the previous formula, in which $k$ is the market share that the firm expects to occupy. In addition, in this method, it is not necessary to estimate each competing firm's amount of advertising budgets but rather to estimate the total volume of advertising injections for a given product, work or service.

Approach 3. Calculation of the advertising budget for residual funds.

The amount of the advertising budget is calculated based on the funds remaining after use for all other needs.

This method is one of the most unsuccessful, as it deprives the advertising policy of the main advantages. Investments in advertising are no different from any other investment. Therefore, advertising costs should be considered on an equal basis with other costs.

Approach 4. Calculation of the advertising budget based on the criterion of optimal advertising costs.

This approach is based on the algorithm for finding the optimal value of the advertising budget according to the maximum ratio of advertising efficiency to its costs. This approach relies heavily on advertising efficiency and marketing budget optimization.

This approach includes the following methods.

Dorfman-Steiner model

$$
q=q(a, p), \frac{d q}{d a}>0, \frac{d q}{d p}>0 . \frac{a t}{p q}=\left(\frac{p-\frac{d T c}{d q}}{p}\right) \frac{a}{q} \frac{d q}{d a}=\frac{1}{|E|} \alpha
$$

The model assumes that a certain firm purchases advertising messages $(\alpha)$ at a price t. Demand function: An increase in advertising spending increases demand, while an increase in price decreases it.

Profit function: $\Pi=p q(a, p)-T C(q(p))-a t$

where $T C_{(q)}$ - costs, excluding advertising.

Thus, on the left - the ratio of advertising costs to total revenue, on the right - the product of the marginal rate of return and the elasticity of demand for advertising. 


$$
\frac{P-M C}{P}=\frac{1}{|E|}
$$

Under a monopoly, the profit-maximizing marginal rate of return is:

$$
\alpha_{a i}=\left(\frac{a_{i}}{Q} \frac{d Q}{d a_{i}}\right)+\left(\frac{a_{i}}{m_{i}} \frac{d m_{i}}{d a_{i}}\right)
$$

In oligopoly conditions, using the Cournot-Nash model, "when the expected advertising costs of a competitor will not change if the costs of the company in question change", we can derive the following relationship: for advertising, $\mathrm{mi}=\mathrm{qi} / \mathrm{Q}$ is the share of the firm in the total output of the industry. The first term is the elasticity of the output of the i-th firm with respect to advertising costs; the second term is the elasticity of changes in the market share of the i-th firm concerning advertising expenses.

Based on this model, we can say that "the optimal share of advertising costs in the company's total revenue is directly dependent on the elasticity of demand for advertising, and inversely - on the price elasticity of demand." This is the Dorfman-Steiner condition.

\section{Danaher-Rust model}

In this method, it is assumed that the effectiveness of advertising, expressed in the relative value of the target audience reach, depends on the cost of advertising as follows:

$$
f=1-\frac{E_{A 0}}{E_{A}}
$$

where $f$-the value of coverage of the target audience (with $100 \%$ coverage $f=1$ );

$E_{A}$ - the amount of advertising costs (the amount of the advertising budget);

$E_{A O}$ - certain coefficient, meaning equal to the amount of advertising costs, at which the effectiveness of advertising is zero $(f=0)$. Obviously, advertising costs equal to or less than EAO do not make economic sense.

Optimization of the coverage/cost ratio: $F=f / E A=1 / E A-E A 0 /-E A 2$.

Differentiating this function by EA and finding this value, we obtain the optimal value of advertising costsEAopt $=2 E A 0$. Let's substitute this value in the formula $\mathrm{F}$ and get the maximum value of the ratio "coverage/cost" Fmax $=1 / 4 E A 0$.

This is a fairly simple variation of the method since $f$ only depends on EA. The original uses the formula:

$$
f=1-\left(\frac{E_{A 0}}{E_{A}}\right)^{k}
$$

where $k$-coefficient that takes into account discounts on advertising with an increase in volume and makes it possible to more accurately take into account the drop in advertising efficiency with an increase in volumefopt $=k /(1+k)$. In general, the algorithm will be the same, but the calculation will be complicated by using natural logarithms.

The latest models are among the most effective, but their main methodological mistake is that the maximum ratio of the target audience coverage and advertising costs is used as a decision criterion. In fact, this ratio is equivalent to the return on investment in advertising.

Suppose the profit is considered proportional to the effectiveness of advertising $f$. In that case, optimization of the ratio of the reach of the target audience and the cost of advertising is tantamount to optimizing the return on investment in advertising. However, the criterion for deciding on the amount of advertising investments cannot be the optimal profitability of these investments.

Suppose an ad module in a given publication costs $\$ 100$, and the profit generated by this ad module is $\$ 50$. Suppose now that a module 2 times larger in the area costs $\$ 200$, and it will bring in 
$\$ 80$ profit. Then the profitability of the 1 st module will be $50 / 100=0.5(50 \%)$, and the profitability of the 2 nd module will be $80 / 200=0.4(40 \%)$. If the enterprise follow the optimality criterion adopted in the Danaher-Rust method, it needs to choose a smaller module in the area. However, in reality, it all depends on the profitability of alternative investments. After all, a small module costs $\$ 100$. But there is still a free second $\$ 100$. If the return on alternative investments of $\$ 100$ is less than 0.3 $(<30 \%)$, then the total return on investment of $\$ 200$ will be less than when taking a larger module. For example, an ad module in another publication will also cost $\$ 100$, but it will bring in $\$ 20$ in profit. Then the total profit will be $50+20=\$ 70$, which is less than the $\$ 80$ that the firm would receive if it took the larger module in the first edition.

From the above reasoning, the following conclusion can be drawn. According to the Danaher-Rust method, if advertising investments are the most profitable, then the advertising budget should not be lower than the optimal value. Further, it all depends on the number of alternative investments. The less they are profitable compared to the profitability of advertising investments, the greater the value of the advertising budget should be relative to the optimal value according to the Danaher-Rust method.

\section{Results and discussion.}

\subsection{Distribution of the advertising budget by channel.}

The main channels used by most marketers have not changed lately. But modern technologies, global digitalization, and pandemic and the crisis have influenced changes in the approach to them and new opportunities available to marketers for each of them.

Table 1. The process of optimizing the enterprise's marketing budget

\begin{tabular}{|c|c|c|}
\hline $\begin{array}{c}\text { Marketing } \\
\text { Channels and marketing tactics }\end{array}$ & $\begin{array}{l}\text { Adjust budget } \\
\text { allocation (\%) }\end{array}$ & $\begin{array}{c}\text { Enterprise marketing } \\
\text { budget by } \\
\text { channel/marketing } \\
\text { tactics }(\$)\end{array}$ \\
\hline Banner advertising & 17 & 170 \\
\hline Social Media Marketing (SMM) & 14 & 140 \\
\hline $\begin{array}{l}\text { Traditional Marketing (Print, Direct Mail, TV, } \\
\text { Radio Advertising) }\end{array}$ & 13 & 130 \\
\hline Email advertising & 10 & 100 \\
\hline Content marketing & 10 & 100 \\
\hline Search Engine Optimization (SEO) & 9 & 90 \\
\hline Contextual (search) advertising (PPC) & 9 & 90 \\
\hline Landing Page / Website & 9 & 90 \\
\hline Affiliate Marketing & 9 & 90 \\
\hline Total & $100 \%$ & $\$ 1000$ \\
\hline
\end{tabular}

For example, marketers love Instagram (the platform reached 2 billion advertisers in 2017). In 2019, Instagram launched Instagram Checkout, which allows users to buy products without ever 
leaving the app. Currently, the platform only works for the US market, but it's worth taking a look at the prospect and using buy posts right now that allow followers to browse products on Instagram and then shop on the enterprise's website.

There is no one-size-fits-all approach to channel budgeting and marketing tactics these days. However, there is a general trend towards a shift from offline media to digital online. Based on the majority of modern, the marketer can deduce the following recommendations to adjust the distribution of the marketing budget by marketing priorities.

The nine main marketing channels are presented in Table 1 with an example of marketing budget allocation.

\subsection{Recommendations for the distribution of the marketing budget.}

\section{Banner advertising.}

Online consumers spend $50 \%$ of their time on the Open Internet, which includes every website outside of closed platforms such as social media and search platforms. But marketers spend only $30 \%$ of their budgets on it. Increase the enterprise's advertising spend on the open web to reach consumers in a less busy environment where it can optimize campaigns for your specific marketing goals, such as increased traffic or sales to the enterprise's site.

\section{SMM}

Social media marketing is based on targeting audiences by demographics and interests (for example, "millennial women" or "people who love sports"). This is why more and more marketers are using social media to build brand awareness rather than conversion campaigns. Increase the enterprise's social media budget if it focuses on top-level tasks in the funnel (Figure 2). Reduce expenses if the enterprise is focused on sales.

\section{Traditional marketing}

Traditional marketing budgets are being cut to make way for digital. It's easier for marketers with smaller budgets to gauge the impact and ROI of digital investment than the budgets invest in most traditional channels. Cut standard marketing budget if the enterprise wants to more attribute the enterprise's marketing budget to its site's traffic and sales.

\section{Email marketing}

Consider email as the most direct communication channel with the enterprise's customers; that is, use it wisely. Increase budget if the enterprise wants to personalize messaging more, such as sending an "abandoned cart" email newsletter that will show customers the items they've viewed and added to their cart but haven't bought yet.

\section{Content marketing}

Content marketing helps to tell the enterprise's brand story. When it is building a brand from scratch, content helps to make strong connections with new customers. Increase content marketing budget if the enterprise is new to the market or a small brand focused on building awareness and expanding the enterprise's customer base. Cut budget if the enterprise wants to increase sales from existing customers.

\section{SEO}

SEO brings the enterprise to the top of search results for specific keywords, which helps find consumers with clear buying intent and get more traffic to the enterprise's site. Increase SEO budget if that's the enterprise's long term goal (it takes time to get to the top). However, research shows that the majority of searches occur on marketplaces such as Amazon and eBay. Reduce costs if the enterprise already uses SEO before, and website traffic remains high-quality.

\section{7. $P P C$}

Unlike SEO, PPC advertising brings the enterprise to the top of search results for chosen keywords. And now retailers are starting to offer native search ads, which is why the enterprise's 
products appear at the top of their results pages. Increase spending if the enterprise's short-term goals are to increase brand awareness and website traffic.

\section{Website and Landing Pages}

The online store site is the enterprise's digital showcase - invest in it like a regular retail store. Consumers will want to stay with the enterprise through negative user experiences. Increase budget if the enterprise's site's bounce rate rises (i.e., more people are leaving without browsing or buying anything). Cut budget if the enterprise has recently updated the enterprise's website and have a reasonable conversion rate.

\section{Affiliate Marketing}

In its simplest form, Affiliate marketing is when someone earns a commission for marketing the enterprise's product: think about influencers, partnership options, and collective discount services. Increase affiliate marketing budget if the enterprise's customer acquisition or conversion campaigns on other channels aren't delivering the wanted results.

\section{Conclusion}

The famous phrase of American entrepreneur John Wanamaker that "Half the money I spend on advertising is wasted; the trouble is I don't know which half" has not lost its relevance today. Almost all companies are faced with the problem of determining the optimal advertising budget, and almost no one can evaluate this magic number. This budget would allow getting one hundred per cent return on advertising. Any deviation from optimality leads to inefficiency: with a smaller budget, the company receives less profit from sales (since not all consumers are aware of the product), with a larger budget, the company simply throws some of the funds down the drain (since all consumers are aware, and additional advertising is not required). Nevertheless, when a company may suffer significant losses due to insufficient advertising, the first situation is more serious than the second, when the company spends money on advertising. The fact that the purpose of advertising is to inform consumers and remind and persuade speaks in favour of the higher level of spending. However, in this case, too, the main question - about the optimal level of the budget - remains open. Many professionals rely on their own experience, common sense and simple interdependencies when calculating an advertising budget. Recently, more complex methods of calculating the advertising budget have appeared, but their assessment and application should not be divorced from practice. The following describes methods for determining advertising costs based on established practice and several theoretical methods that deserve all involved in solving this difficult task.

As practice shows, the problem of determining the optimal advertising budget does not have an absolute solution. However, this does not mean that companies have no benchmarks in this area. In each case, technical calculations should be preceded by a thorough analysis of the situation and existing methods for determining the advertising budget. Searching for suitable ways and their "tuning" to a specific situation can prevent large financial losses and significantly increase the effectiveness of an advertising campaign.

Getting the proper marketing budget for the enterprise is both an art and a science. Whether the enterprise's annual budget is $\$ 1$ million or $\$ 1,000$, every marketer and small business owner wants their brand not to get lost in the crowd. The enterprise's task is to optimize costs and get the most out of business.

Simultaneously, the enterprise must keep up with the constant changes in the digital marketing landscape and be ready to try new channels that consumers are using and higher profits. This flexibility and willingness to test and train will take the enterprise's bottom line to the next level. 


\section{References}

1. Il'ashenko, S. (2004). The definition of necessary and sufficient information accumulation level to substantiate a choice of enterprise's market opportunities directions development. Problems and Perspectives of Management, 1, pp. 138-153.

2. Chukhray, N.I., Kulyniak, I.Y. (2015). Marketing research on Lviv region enterprises readiness to entering EU markets. Actual Problems of Economics, 173(11), pp. 77-86.

3. Güler, M.G. (2021). An analysis on the marketing budget of a newsvendor. Operational Research. DOI: 10.1007/s12351-021-00621-w

4. Koval, V., Kovshun, N., Plekhanova, O., Kvitka, S., Haran, O. (2019). The role of interactive marketing in agricultural investment attraction. International Multidisciplinary Scientific GeoConference Surveying Geology and Mining Ecology Management, SGEM, 19, pp. 877-884.

5. Shpak, N., Kulyniak, I., Gvozd, M., Malynovska, Y., Sroka, W. (2020). Estimation of the marketing activity of banking structures. Acta Universitatis Agriculturae et Silviculturae Mendelianae Brunensis, 68(1), pp. 229-242.

6. Piano, E.E., Rouanet, L. (2020). Economic calculation and the organization of markets. The Review of Austrian Economics, 33(3), pp. 1-18. DOI: 10.1007/s11138-018-0425-4

7. Fan, X., Zhang, J., Zhu, G. (2020). Effects of consumers' uncertain valuation-for-quality in a distribution channel. Annals of Operations Research. DOI: 10.1007/s10479-020-03847-7

8. Koraus, A., Stefko, R., Dobrovic, J. (2016). Decision-making satisfaction and behaviour of bank customers: Survey results analysis. Actual Problems of Economics, 186(12), pp. 291-301.

9. Bashynskaya, I. (2012). An evaluation of performance integrated marketing communications: use of the "funnel efficiency" method. Proceedings of Odessa Polytechnic University: Scientific and research and production collection, 2(39), pp. 330-334.

10. Świeczak, W. (2013). Marketing automation processes as a way to improve contemporary marketing of a company. DOI: 10.14611/minib.09.03.2013.12

11. Hughes, C., Van Gilse, M. (1991). The how and why of a marketing budget. Administrative radiology, 10(11), pp. 51-57.

12. Koosha, H., Albadvi, A. (2020). Allocation of marketing budgets to maximize customer equity. Operational Research, 20(4). DOI: 10.1007/s12351-017-0356-z 